\title{
Program "Jari Peri" untuk meningkatkan keterampilan dan efikasi mengajar prevensi Kekerasan Seksual pada Anak (KSA)
}

\author{
Dina Wahida ${ }^{* 1}$, Ira Paramastri ${ }^{2}$ \\ $\left.{ }^{*}\right), 2$ Universitas Gadjah Mada \\ Koresponding Email: dina.wahida@ugm.ac.id
}

\begin{abstract}
The child sexual abuse (CSA) is coercion or threat of a child in sexual activity of adults or the opposite sex of peers. The sexual abuse is not only occurred among children in general, but also occurred in children with special needs, because they do not familiar with the vital organs that should be protected (e. g vagina, breast, penis, and buttocks). This is able to make a trauma, either physical, psychological or social. Ironically, this incident is not always reported to the authorities or child protection agencies. For this incident does not increase, it needs to take a strategy primary prevention. The purpose of this study is to determine how effective the program of "jari peri" (the teachers teach self protection) to improve skills and teacher's efficacy for the prevention of child sexual abuse. The method used in this study was quantitative method with quasiexperimental; the unreated control group design with multiple dependent pretest and posttest. Statistical test used was mixed design ANOVA. Efficacy scale was used to determine the increase in teacher efficacy, checklist skill of verbal and non-verbal communication to determine the increase in teacher's skill and knowledge manipulation checks used to determine the increase in teacher's understanding. Twenty teachers of educated specialschool SLB-C P and SLB-C N in Yogyakarta were selected purposively. The result showed comparation between experiment and control group which have significant difference for skill of delivering CSA prevention ( $F=127,447 ; p<0.05)$ and there is not significant difference for efficacy teaching CSA prevention ( $F=3.560 ; p>0.05)$. Therefore program of "jari peri" can improve skill of delivering CSA prevention to the SLB-C teacher, but it can not improve the efficacy of teaching prevention of CSA on teacher of SLB-C.
\end{abstract}

Keywords: Chid Sexual Abuse, Psychoeducation, Teaching efficacy

\begin{abstract}
Abstrak. Kekerasan seksual pada anak (KSA) merupakan pemaksaan atau ancaman seorang anak dalam aktivitas seksual yang dilakukan orang dewasa atau teman sebaya. Kekerasan seksual tidak hanya terjadi dikalangan anak-anak pada umumnya namun juga terjadi pada anak yang berkebutuhan khusus, karena mereka belum dapat mengenal dengan baik organ vital yang harus dilindungi (misal vagina, payudara, penis, dan pantat). Hal tersebut dapat menjadikan trauma baik fisik, psikologis maupun sosial. Ironisnya kejadian ini tidak selalu terlaporkan baik kepada pihak yang berwenang ataupun lembaga perlindungan anak. Agar kejadian ini tidak semakin meningkat, maka dibutuhkan suatu strategi prevensi primer. Penelitian ini bertujuan untuk mengetahui apakah progam "Jari Peri" (guru ajari perlindungan diri) dapat meningkatkan keterampilan dan efikasi mengajarkan prevensi KSA. Penelitian ini menggunakan metode kuantitatif dengan rancangan eksperimen kuasi the untreated control group design with multiple dependent pretest and posttest. Uji statistik menggunakan mixed design ANOVA. Skala efikasi digunakan untuk mengetahui peningkatan efikasi mengajar guru, cheklis keterampilan komunikasi verbal dan non verbal untuk mengetahui peningkatan keterampilan guru dan cek manipulasi pengetahuan digunakan untuk mengetahui peningkatan pemahaman guru. Dua puluh orang guru SLB-C P dan SLB-C N di Yogyakarta diseleksi secara purposive. Hasil analisis menunjukkan perbandingan antara kelompok eksperimen dan kontrol mempunyai perbedaan signifikan untuk keterampilan menyampaikan prevensi KSA (127, 447; $p<0.05)$, dan tidak ada perbedaan signifikan untuk efikasi mengajar prevensi KSA (F=3.560;p>0.05). Artinya, program "jari peri" dapat meningkatkan keterampilan menyampaikan prevensi KSA pada guru SLB-C, namun tidak dapat meningkatkan efikasi mengajar prevensi KSA pada guru SLB-C.
\end{abstract}

Kata kunci: Kekerasan seksual anak, psikoedukasi, efikasi mengajar 


\section{Pendahuluan}

Kekerasan seksual tidak hanya terjadi dikalangan anak pada umumnya tetapi juga terjadi pada anak yang berkebutuhan khusus. Hasil wawancara dengan beberapa guru Sekolah Luar Biasa (SLB) di Yogyakarta menyatakan bahwa, anak-anak yang mengalami keterbelakangan mental banyak yang menjadi korban kekerasan seksual oleh orang dewasa disekelilingnya. Guru SLB menambahkan ada salah satu siswa SLB-C pernah mengalami perkosaan oleh anak jalanan dan tukang becak di sekitar rumahnya, tetapi siswa tersebut tidak mengerti bahwa hal tersebut merugikan dirinya dan dapat menjadikan trauma fisik (wawancara dengan Guru SLB-C N YK, 2012).

Kasus lain adalah banyaknya siswa SLB yang tidak paham dan tidak mengenal fungsi dan cara melindungi organ vital yang dimiliki, sehingga siswa sering memperlihatkan alat kelaminnya didepan orang lain atau teman dan sering mencoba melakukan masturbasi. Kejadian tersebut terjadi karena siswa tidak pernah menerima pendidikan kesehatan reproduksi, pentingnya melindungi organ vital dan fungsi dari organ vital yang dimiliki, serta pemahaman mengenai kekerasan seksual pada anak. Selain itu kurangnya pengawasan dari orang dewasa di sekitarnya, baik orangtua ataupun guru di sekolah (wawancara dengan Guru SLB-C N YK, 2012).

Wawancara dengan guru SLB-C PYK (2013) mengatakan, beberapa siswa berkebutuhan khusus menjadi pelaku dan korban kekerasan seksual di sekolah, terutama siswa yang sudah menginjak masa remaja. Beberapa waktu lalu siswa SMP menyeret teman perempuannya ketempat yang sepi dan tidak ada orang, kemudian siswa tersebut memaksa teman perempuan untuk membuka baju kemudian meraba area dada dan alat kelaminnya, ironisnya teman perempuan justru menikmati hal tersebut, tidak paham bahwa kekerasan seksual dapat berdampak negatif terhadap dirinya. Sejauh ini guru sudah berupaya untuk mengatasi hal tersebut, tetapi belum semua guru melaksanakan dan tidak konsisten sehingga kekerasan seksual terhadap anak di sekolah tersebut masih belum tertangani.

Levy \& Packman (2004) mengatakan frekuensi kekerasan seksual pada anak berkebutuhan khusus lebih besar dari pada anak normal pada umumnya. Anak-anak yang mengalami kekerasan fisik sebagian besar terlibat dalam perilaku kekerasan seksual, memiliki permasalahan perilaku dan permasalahan akademis serta melakukan upaya bunuh diri (Mandell, Walrath, Manteuffel, Sgro \& Pinto-Martin, 2005).

Anak berkebutuhan khusus yang mengalami kekerasan seksual dialami oleh anak autis dan retardasi mental (Gorczyca, Gorczyca, Ziora, \& Oświęcimska, 2007., McClellan, 1996). Penelitian menunjukkan anak yang mengalami retardasi mental pernah mengalami kekerasan seksual yang dilakukan oleh orang dewasa dan sebagain besar tidak menyadari dan mengerti bahwa dirinya mengalami kekerasan seksual yang dilakukan oleh keluarga dan pengasuhnya sendiri. Kekerasan fisik dan kekerasan seksual pada anak terjadi di rumah, sekolah, angkutan umum dan di tempat lain (Cederborga, Hultmanb, \& Rooyc, 2011; Heather, Turner, Vanderminden, Finkelhor, Hamby, \& Shattuck, 2011; Kvam, 2005., Morano, 2001)., Kvam, 2004).

Banyak kasus kekerasan seksual pada Anak Berkebutuhan Khusus (ABK) yang tidak terlaporkan dan tidak diketahui oleh orangtua, guru, pihak yang berwenang ataupun lembaga perlindungan anak sehingga dapat menimbulkan trauma bagi anak, baik fisik, psikologis maupun sosial (Hall \& Hall, 2011; Lovett, 2004; National Catholic Services, 2003; Smith, 2012; Trickett, Noll, \& Putnam, 2011). Finkelhor, Hammer \& Sedlak (2008), mengatakan banyak anak-anak tidak pernah memberitahu siapapun tentang apa yang terjadi pada mereka. Hal ini sebagai akibat dari ancaman atau manipulasi oleh pelaku, akibatnya sebagian besar kasus tidak pernah dilaporkan ke polisi. Agar kejadian ini tidak semakin meningkat, maka dibutuhkan suatu strategi prevensi primer. Prevensi dapat dilihat sebagai suatu 
proses mengubah perilaku potensial, pelaku, korban dan lingkungan dengan mentargetkan pelayanan kepada masyarakat umum yang bertujuan untuk menghentikan suatu kejadian (Daro, 1994). Dasar prevensi dan intervensi kasus-kasus penyimpangan individu, yaitu: (1) meningkatkan kekuatan individu (Increasing individual strengths) dan mengurangi kelemahan individu (decreasing individual limitation), (2) meningkatkan dukungan sosial (increasing social support) dan mengurangi tekanan sosial (decreasing social stresses), dan (3) meningkatkan kemudahan yang ditimbulkan dari lingkungan fisik dan mengurangi kesulitan yang ditimbulkan dari lingkungan fisik (Bloom, 1996).

Prevensi primer diterapkan dalam tatanan sekolah, dilakukan melalui psikoedukasi pelatihan yang diberikan oleh guru SLB-C sebagai agen pengubah pencegahan kekerasan seksual pada anak. Sekolah sebagai institusi pendidikan bertanggung jawab mentransformasikan ilmu pengetahuan kepada siswanya (Barron \& Topping, 2003; Larsen, Andersen \& Plauborg, 2010; Skarbek, Hahn dan Parrish, 2011). Sekolah merupakan lokasi yang stategis dan efektif untuk pencegahan kekerasan seksual pada anak berkebutuhan khusus, yang diberikan melalui guru di sekolah.

Pemilihan Sekolah Luar Biasa (SLB) karena, anak berkebutuhan khusus secara fisik berkembang seperti anak-anak pada umumnya begitu juga dengan perkembangan seksualnya, sementara anak yang mengalami keterbelakangan mental tidak mengerti dan belum paham mengenai organ vital, pendidikan seks serta kekerasan seksual pada anak (Abramson, 2002; Morano, 2001). Pemberian edukasi yang tepat, guru dapat membantu siswa untuk mengenali situasi bahaya dan mencegah terjadinya KSA khususnya di lingkungan sekolah (Bagisnky \& Macpherson, 2005; Finkelhor, 2009). Penelitian yang dilakukan oleh Paramastri, Prawitasari, Prabandari, \& Ekowarni, (2011) mengenai guru SD sebagai agen pengubah untuk prevensi terhadap kekerasan seksual pada anak, menyebutkan meningkatnya pengetahuan dan pencegahan pada guru tentang KSA.

Guru memegang peran yang paling berpengaruh dalam proses belajar mengajar di sekolah, terutama sebagai contoh atau model yang selanjutnya ditiru oleh peserta didik sesuai dengan pandangan teori kognitif sosial. Teori kognitif sosial memandang bahwa manusia dapat belajar dari pengalaman langsung, tetapi lebih banyak yang mereka pelajari dari aktivitas mengamati perilaku orang lain. Informasi akan lebih banyak tertahan dalam proses kognitif dan perkembangan sosial, sehingga manusia memiliki pengetahuan dan keterampilan (Bandura, 1986).

Melalui program yang diberikan dalam penelitian ini, guru akan diberikan pengetahuan dan keterampilan prevensi KSA yang berbentuk psikoedukasi pelatihan. Psikoedukasi pelatihan dalam penelitian ini akan mengajarkan guru untuk menyampaikan prevensi KSA kepada anak berkebutuhan khusus yang sudah remaja atau memasuki masa pubertas, dan tergolong anak SLB-C mampu didik (educable).

Prevensi primer yang dilakukan pada penelitian ini menggunakan psikoedukasi pelatihan. Menurut Nelson-Jones (1982) psikoedukasi merupakan suatu usaha yang membantu mengembangkan aneka life skills atau keterampilan hidup melalui aneka program terstruktur yang diselenggarakan berbasis kelompok. Beberapa life skills meliputi, kemampuan memahami orang lain secara empatik, kemampuan menyelesaikan masalah dan membuat perencanaan, dan kemampuan menjalani aneka transisi kehidupan secara efektif.

Psikoedukasi dalam penelitian ini adalah program "jari peri" yaitu program guru ajari perlindungan diri kepada siswa, "jari peri" disimbolkan sebagai seorang guru yang menjadi agen untuk melakukan pencegahan KSA kepada siswa SLB- C dan menolong siswa dari bahaya KSA di sekolah. Program "jari peri" menggunakan media bantuan vidio, flipchart dan gambar dalam menjelaskan materi KSA dan pencegahanya dan disajikan dalam bentuk pelatihan. Melalui psikoedukasi pelatihan diharapkan guru dapat mengimplementasikan ilmu yang didapatkan dari psikoedukasi yang selanjutnya akan diajarkan kepada siswa berkebutuhan khusus yang sudah memasuki masa pubertas. 
Penelitian ini bertujuan untuk mengetahui apakah progam "jari peri" (guru ajari perlindungan diri) dapat meningkatkan keterampilan menyampaikan dan efikasi guru SLB-C dalam mengajarkan prevensi kekerasan seksual pada anak (KSA). Terdapat dua hipotesis dalam penelitian ini yaitu; (1) program "jari peri" (guru ajari perlindungan diri) dapat meningkatkan keterampilan menyampaikan prevensi KSA pada guru SLB-C; (2) program "jari peri" (guru ajari perlindungan diri) dapat meningkatkan efikasi mengajar prevensi KSA pada guru Sekolah Luar Biasa-C. Manfaat penelitian secara praktis, penelitian ini dapat membantu para guru untuk menghadapi permasalahan perkembangan $A B K$, dan melakukan pencegahan kekerasan seksual secara dini pada ABK.

\section{Metode}

Identifikasi variabel dan subjek penelitian

Variabel tergantung dalam penelitian ini adalah keterampilan menyampaikan prevensi KSA dan efikasi mengajar prevensi KSA. Variabel bebas dalam penelitian ini adalah psikoedukasi tentang prevensi KSA yang berbentuk program "jari peri" yaitu, guru ajari perlindungan diri terhadap siswa. Pemilihan subjek secara non random. Subjek dalam penelitian ini adalah guru SLB-C P dan SLB-C N di Yogyakarta. SLB-C merupakan SLB untuk anak dengan keterbalakangan mental atau anak yang mengalami retardasi mental. Terdapat dua tipe siswa SLB-C yaitu, mampu didik (educable) dan mampu latih (trainable). Guru dalam penelitian ini adalah guru yang memiliki siswa SLB-C yang sudah memasuki masa pubertas dan mampu didik (educable) yang berjumlah 20 guru, dan dipilih secara purposif. SLB-C P sebagai kelompok eksperimen dan SLB-C N sebagai kelompok kontrol. Kelompok eksperimen dan kelompok kontrol terdiri atas 10 orang guru. Karakteristik subjek penelitian adalah guru SLB-C P dan SLB-C N, bersedia untuk mengikuti program "jari peri", menjabat sebagai guru wali kelas/bimbingan konseling/PA/olah raga, dan efikasi mengajarkan prevensi KSA dalam kategori rendah dan sedang, serta belum pernah mengikuti program prevensi KSA.

\section{Instrumen penelitian}

Penelitian ini menggunakan instrumen berupa tes pemahaman prevensi terhadap KSA yang dimodifikasi dari Paramastri (2011), disusun berdasarkan aspek-aspek prevensi terhadap KSA, yaitu 1) pengetahuan tentang kekerasan seksual pada anak; 2) pengenalan, nama dan fungsi organ genital; 3) mengatakan "tidak" pada tindakan orang lain yang membuat tidak nyaman; 4) melaporkan kepada orang dewasa ketika terjadi KSA; dan pemahaman mengenai perkembangan remaja.

Observasi keterampilan verbal dan non verbal dalam menyampaikan prevensi KSA menggunakan lembar ceklis observasi keterampilan verbal dan non verbal dalam menyampaikan prevensi KSA yang disusun oleh Wijayanti (2013) dengan $\mathrm{r}=0,810$. Metode observasi menggunakan event sampling dilakukan saat pretes dan postes saat guru menyampaikan materi prevensi KSA pada siswa yang sudah remaja atau memasuki masa pubertas dan tergolong siswa SLB-C mampu didik (educable). Penilaian observasi menggunakan ratingscale dengan pilihan keterangan dari 1 sampai 5 (1=sangat kurang sampai $5=$ sangat baik).

Skala efikasi bertujuan untuk mengukur efikasi guru dalam mengajarkan prevensi KSA pada siswa SLB-C. Skala efikasi mengajar dimodifikasi dari skala yang disusun oleh Hadjam dan Widhiarso (2011) 
dengan $r=0,853$ pada perencanaan mengajar, $r=0,838$ pada pelaksanaan mengajar dan $r=0,835$ pada evaluasi hasil belajar. Skala efikasi guru di susun berdasarkan aspek-aspek efikasi mengajar guru: a) perencanaan mengajar; b) pelaksanaan mengajar; dan c) evaluasi hasil belajar.

\section{Rancangan dan prosedur Penelitian}

Penelitian ini merupakan penelitian eksperimen kuasi. Rancangan yang digunakan dalam penelitian ini adalah the untreated control group design with multiple depedent pretest and posttest (Shadish, Cook \& Campbel, 2002), yang merupakan bagian dari rancangan eksperimen dua kelompok (between subject design), yang dirancang dengan membagi tanpa penugasan secara random ke dalam kelompok eksperimen dan kontrol. Pretes diberikan kepada kelompok eksperimen dan kelompok kontrol. Adapun pretes yang diberikan adalah: tes pemahaman, ceklis keterampilan dan skala efikasi mengajar prevensi KSA pada kelompok eksperimen dan kelompok kontrol. Psikoedukasi pada kelompok eksperimen, dilaksanakan selama 2 kali pertemuan selama 4 jam dalam setiap pertemuan (22-23 Oktober 2013). Postes diberikan kepada kelompok eksperimen dan kelompok kontrol. Adapun postes yang diberikan adalah: tes pemahaman (cek manipulasi), ceklis keterampilan menyampaikan dan skala efikasi mengajar prevensi KSA pada kelompok eksperimen dan kelompok kontrol.

\section{Analisis data}

Analisis data yang digunakan dalam penelitian ini adalah mixed design ANOVA (Field, 2005), karena memadukan dua sub analisis yaitu within subject test dan between subject test. Within subject test adalah pengujian perbedaan skor dalam satu kelompok (pretest-posttest), sedangkan between subject test adalah pengujian perbedaan skor antar kelompok eksperimen dan kelompok kontrol. Selain melakukan analisis untuk mengetahui perbedaan hasil dari perlakuan, peneliti juga menghitung sumbangan efektif perlakuan terhadap keterampilan dan efikasi mengajar prevensi KSA pada guru. Hal ini ditujukan untuk mengetahui sejauh mana besar efek perubahannya (Coe, 2002).

\section{Hasil Penelitian}

Tabel 1. Deskripsi statistik data keterampilan menyampaikan dan efikasi mengajar prevensi KSA pada kelompok eksperimen dan kelompok kontrol

\begin{tabular}{lcccc}
\hline & $\mathrm{N}$ & Ekperimen- kontrol & Mean & Std. Deviation \\
\hline \multirow{2}{*}{ Pretes Keterampilan } & 10 & KE & 34,50 & 4,696 \\
\cline { 2 - 5 } & 10 & KK & 33,30 & 3,056 \\
\hline Postes Keterampilan & 10 & KE & 58,40 & 2,221 \\
\cline { 2 - 5 } & 10 & KK & 35,80 & 2,674 \\
\hline Pretes Efikasi & 10 & KE & 31,30 & 4,056 \\
\hline Postes Efikasi & 10 & KK & 25,10 & 2,131 \\
& 10 & KE & 37,70 & 4,498 \\
\hline & 10 & KK & 28,20 & 2,699 \\
\hline
\end{tabular}

Besarnya nilai deviasi standar skor keterampilan menyampaikan dan efikasi mengajar prevensi KSA dibanding kelompok eksperimen menunjukkan, skor keterampilan dan efikasi kelompok eksperimen lebih bervariasi dibanding dengan kelompok kontrol (tabel 1). Dilihat dari perubahan deviasi standar skor pretes dan postes pada keterampilan dan efikasi cukup besar, maka dapat 
disimpulkan bahwa peningkatan keterampilan dan efikasi pada kelompok eksperimen cukup bervariasi. Artinya ada subjek yang mengalami peningkatan keterampilan menyampaikan dan efikasi mengajar prevensi KSA yang kecil, dan ada yang mengalami peningkatan keterampilan menyampaikan dan efikasi mengajar prevensi KSA yang besar (Widhiarso, 2011).

Tabel 2. Uji hipotesis within subject keterampilan menyampaikan dan efikasi mengajar prevensi KSA

\begin{tabular}{lccc}
\hline \multicolumn{1}{c}{ Variabel } & df & Uji Hipotesis (F) within subject & Sig. \\
\hline Keterampilan & 1 & 127,447 & .0001 \\
\hline Efikasi & 1 & 3.560 & .075 \\
\hline
\end{tabular}

Keterangan: Uji hipotesis signifikan pada tingkat $\mathrm{p} \varangle 0,05$

Tabel 2 menguji perbedaan skor pretes dan postes dalam satu kelompok (within subject) di atas menunjukkan hasil $\mathrm{F}=127,447$ dengan $\mathrm{p}=0,001(\mathrm{p} \varangle 0,05)$ untuk keterampilan menyampaikan prevensi KSA. Hal ini menunjukkan terdapat interaksi antar waktu (pretes-postes) dalam kelompok eksperimen. Interaksi ini menunjukkan bahwa perubahan skor pretes ke postes keterampilan menyampaikan prevensi KSA adalah berbeda secara signifikan. Sementara hasil $F=3,560$ dengan $p=0,07(p>0,05)$ untuk efikasi mengajar prevensi KSA. Hasil analisis tidak menunjukkan adanya interaksi antar waktu (pretespostes) dalam kelompok eksperimen, artinya tidak ada perbedaan pada efikasi mengajarkan prevensi KSA antara kelompok yang diberi perlakuan (kelompok eskperimen) dengan kolompok yang tidak diberikan perlakuan (kelompok kontrol). Kesimpulannya program "jari peri” guru ajari perlindungan diri ini berpengaruh terhadap keterampilan menyampaikan prevensi KSA pada kelompok eksperimen secara signifikan, akan tetapi tidak berpengaruh terhadap efikasi mengajar prevensi KSA.

Program "jari peri" (guru ajari perlindungan diri) dapat meningkatkan keterampilan menyampaikan prevensi KSA pada guru SLB-C. Namun tidak dapat meningkatkan efikasi mengajar guru SLB-C, artinya tidak ada perbedaan efikasi mengajar prevensi KSA antara kelompok eskpereimen dengan kelompok kontrol.

Tabel 3. Uji lanjutan between subject test selisih rerata keterampilan menyampaikan prevensi KSA

\begin{tabular}{c|c|r}
\hline Eksperimen-kontrol & Mean Difference (I-J) & Sig. $^{\text {a }}$ \\
\hline \multirow{2}{*}{ Eksperimen } & $-23.900^{*}$ & .0001 \\
\hline \multirow{2}{*}{ Kontrol } & $23.900^{*}$ & .0001 \\
\hline
\end{tabular}

Keterangan: Mean difference: selisih rerata; (I) time; pengukuran saat pretes; (J) time: pengukuran saat postes. Mean difference signifikan pada tingkat 0,05

Tabel 3 menunjukkan bahwa pelatihan "jari peri" (guru ajari perlindungan diri) dapat meningkatkan keterampilan menyampaikan prevensi KSA pada kelompok ekperimen secara signifikan. Hasil tersebut juga menunjukkan bahwa terjadi perbedaan mean yang signifikan diantara kelompok yang diberi pelatihan (kelompok eksperimen) dengan kelompok yang tidak diberikan pelatihan (kelompok kontrol).

Tabel 4. Ringkasan sumbangan efektivitas keterampilan menyampaikan

\begin{tabular}{lcrrrrr}
\hline & Kelompok pelatihan & Value & F & Error df & Sig & \multicolumn{2}{c}{ Partial Eta Squared } \\
\hline Keterampilan & KE & .054 & $317.928^{a}$ & 18 & .0001 & .946 \\
\cline { 2 - 7 } menyampaikan & KK & .838 & 3.479 a & 18 & .079 & .162 \\
\hline
\end{tabular}

Keterangan: Partial eta squared: sumbangan efektivitas 
Sumbangan efektif pelatihan pada kelompok eksperimen sebesar 0,946 untuk keterampilan menyampaikan prevensi KSA. Artinya pelatihan yang diberikan pada kelompok eksperimen memberikan kontribusi sebesar 94,6 \% terhadap perubahan keterampilan menyampaikan prevensi KSA (tabel 4).

\section{Pembahasan}

Hasil analisis menunjukkan hasil $\mathrm{F}=127,447$ dengan $\mathrm{p}=0,001 \quad(\mathrm{p} \varangle$,05) untuk keterampilan menyampaikan prevensi KSA. Hal ini menunjukkan terdapat interaksi antar waktu (pretes-postes) dalam kelompok eksperimen. Interaksi ini menunjukkan bahwa, perubahan skor pretes ke postes keterampilan menyampaikan prevensi KSA adalah berbeda secara signifikan. Selain itu terdapat interaksi antara kelompok eksperimen dan kelompok kontrol, yaitu kelompok eksperimen menunjukkan skor keterampilan prevensi KSA lebih tinggi dibandingkan dengan kelompok kontrol. Sementara didapatkan hasil $F=3,560$ dengan $\mathrm{p}=0,07(\mathrm{p}>0,05)$ pada efikasi mengajar prevensi KSA. Hal ini menunjukkan tidak ada interaksi antar waktu (pretes-postes) dalam kelompok eksperimen.Interaksi ini menunjukkan bahwa perubahan skor pretes ke postes efikasi mengajarkan prevensi KSA adalah tidak berbeda. Artinya tidak ada perbedaan pada efikasi mengajarkan prevensi KSA antara kelompok yang diberi perlakukan (kelompok eskpereimen) dengan kolompok yang tidak diberikan perlakuan (kelompok kontrol).

Dengan demikian dapat dikatakan bahwa, program "jari peri" (guru ajari perlindungan diri) dapat meningkatkan keterampilan menyampaikan prevensi KSA pada guru SLB-C. Keterampilan menyampaikan prevensi KSA kelompok eksperimen lebih tinggi daripada kelompok kontrol. Namun program "jari peri" tidak dapat meningkatkan efikasi mengajar guru SLB-C, artinya tidak ada perbedaan efikasi mengajar prevensi KSA antara kelompok eksperimen dengan kelompok kontrol.

Hasil analisis data tersebut mendukung hipotesis pada penelitian ini bahwa program "jari peri" (guru ajari perlindungan diri) dapat meningkatkan keterampilan menyampaikan prevensi KSA pada guru SLB-C. Keterampilan menyampaikan prevensi KSA pada kelompok eksperimen lebih tingggi daripada kelompok kontrol, walaupun program "jari peri" tidak dapat meningkatkan efikasi mengajar prevensi KSA pada guru SLB-C. Hal ini didukung oleh penelitian yang dilakukan Baginsky (2005), bahwa pemberian pengetahuan tentang prevensi KSA kepada guru dan pengajaran proteksi diri pada siswa, dapat meningkatkan tanggung jawab guru terkait proteksi diri anak terhadap KSA. Penelitian lain yang dilakukan Jacobsen (1993), menyatakan bahwa pelatihan tentang program identifikasi, intervensi dan prevensi KSA yang diberikan kepada guru, dapat meningkatkan pengetahuan dan keterampilan guru dalam mengidentifikasi, melakukan intervensi dan prevensi KSA. Hasil penelitian yang dilakukan Gidycz \& Davis, 2000 (dalam Topping \& Barron, 2009), bahwa program berbasis sekolah untuk prevensi KSA efektif untuk mengingkatkan pengetahuan, kesadaran dan keterampilan dalam melakukan prevensi KSA. Program tersebut melibatkan guru, relawan, pakar ahli kesehatan mental, fasilitator siswa SMA, anggota staf, pengasuh anak ataupun orangtua. Program berbasis sekolah untuk prevensi KSA rata-rata diberikan sebanyak empat sampai lima sesi sudah efektif. Sesi tersebut mencakup tentang pengertian KSA, dampak KSA, pelaku KSA, keterampilan untuk perlindungan diri dari KSA dan peran guru atau pihak yang terkait dalam penelitian untuk prevensi KSA (Finkelhor 1995a , 1995b dalam Topping \& Barron, 2009).

Peningkatan keterampilan pada kelompok eksperimen dipangaruhi oleh adanya media pendukung dan kondisi siswa yang sama sesuai dengan kondisi belajar mengajar sehari-hari, sehingga ketika 
pemberian materi prevensi KSA pada saat postes, guru paham tentang karakteristik siswanya dan mudah menguasai kondisi kelas. Akhirnya dapat menunjukkan keterampilan menyampaikan prevensi KSA dengan baik. Hal ini menyebabkan hasil skor pada keterampilan menyampaikan prevensi KSA sangat tinggi $(\mathrm{F}=127,447)$. Selain itu, kondisi siswa yang sama bagi guru kelas saat postes, sehingga memudahkan guru untuk memahami karakteristik siswa.

Peningkatan keterampilan menyampaikan prevensi KSA pada kelompok eksperimen dipengaruhi oleh proses pembelajaran. Bandura (1986) mengatakan manusia dapat belajar dari pengalaman langsung, namun lebih banyak yang mereka pelajari dari aktivitas mengamati perilaku orang lain. Pengetahuan yang diperoleh dari aktivitas mengamati akan lebih banyak tertahan dalam proses kognitif dan perkembangan sosial. Peserta kelompok ekpserimen yang mendapat pelatihan telah melakukan pengamatan (observasi) dalam proses menyampaian informasi, kemudian dijadikan pengetahuan yang bermakna dan disimpan dalam ranah kognitif.

Inti dari belajar melalui observasi adalah pemodelan (modelling), belajar melalui pemodelan mencakup penambahan dan pencarian perilaku yang diamati, kemudian melakukan generalisasi dari suatu pengamatan kepengamatan lain. Artinya, pemodelan melibatkan proses-proses kognitif, tidak hanya meniru, lebih sekedar menyesuaikan diri dengan tindakan orang lain, karena sudah melibatkan representasi informasi secara simbolis dan menyimpannya untuk digunakan di masa depan (Bandura, 1986). Pemodelan yang dilakukan peserta dalam pelatihan "jari peri" ini terkait dengan alur pemberian materi saat postes, yaitu dalam menjelaskan diawali dengan pembukaan seperti menceritakan kasus sederhana tentang pacaran yang mengarah pada tindakan KSA. Kemudian peserta menjelaskan hal terkait tentang KSA sesuai dengan perkembangan kognisi anak didik dan menggunakan bahasa yang mudah dimengerti siswa. Pemberian informasi yang berulang-ulang kepada siswa, hal ini karena siswa yang ditangani adalah siswa berkebutuhan khusus. Selain itu, meminta siswa untuk memberikan tanggapan tentang materi yang disampaikan, hal ini dilakukan sebagai evaluasi apakah materi yang guru sampaikan dapat dipahami siswa.

Peserta pada kelompok eksperimen melakukan pemodelan atas apa yang telah mereka observasi selama pelatihan. Hal ini terlihat pada saat postes guru menyampaikan prevensi KSA menggunakan cara-cara yang dilakukan oleh fasilitator dalam proses pelatihan seperti penggunaan media pendukung, namun ada juga cara-cara yang sudah dimodifikasi oleh para guru. Salah satunya menggunakan kisah hidup siswanya mulai dari kecil hingga dewasa menggunakan gambar, hal tersebut bertujuan untuk mengenalkan jenis kelamin dan status dalam keluarga, agar siswa berkebutuhan khusus mengerti bahwa dirinya harus melindungi diri dari siapapun termasuk keluarganya sendiri. Media pendukung lain yang digunakan guru ketika pemberian materi prevensi KSA kepada siswa (postes) adalah dengan flip-chart yang berisi tentang pengenalan jenis kelamin, bagian tubuh yang harus dilindungi, ramburambu KSA atau hal yang boleh dan tidak boleh dilakukan siswa terhandap situasi mengarah pada KSA. Hal ini menyebabkan skor keterampilan menyampaikan prevensi KSA pada kelompok eksperimen mengalami kenaikan.

Pernyataan tersebut didukung oleh beberapa penilitian yang dilakukan Hazzard, 1991; Herbert, 2001; Taal \&Edelaar , 1997; Telljohann, 1997; . Tutty , 1992, 1994 (dalam Topping \& Barron, 2009), menunjukkan bahwa program prevensi KSA efektif untuk meningkatkan pengetahuan dan keterampilan dengan sumbangan efektif yang cukup tinggi. Hal ini karena program tersebut diberikan dengan menggunakan modeling, dikusi kelompok dan role-play. Peserta yang mengikuti program dapat melihat, menggapi dan belajar dari modeling peserta lain atau fasilitator dalam program tersebut, sementara diskusi kelompok membuat peserta memiliki pengatahuan tentang KSA yang sebelumnya belum diketahui, sedangkan role-play membuat peserta melatih keterampilan dalam prevensi KSA (Topping \& Barron, 2009). 
Bandura (1986) mengatakan terdapat empat proses yang mengatur pembelajaran dengan observasi, yaitu:1) Perhatian; 2) Representasi; 3) Produksi perilaku; 4) Motivasi. Selama pelatihan peserta mengalami proses pemberian perhatian. Fasilitator dalam pelatihan ini adalah psikolog yang sudah memiliki pengalaman tentang anak berkebutuhan khusus, dan sudah terbiasa menangani kasus-kasus anak berkebutuhan khusus bagitu juga tentang KSA pada anak berkebutuhan khusus. Sehingga fasilitator sering menceritakan pengalaman nyata kepada peserta terkait kasus-kasus KSA ketika pelatihan berlangsung. Oleh karena itu peserta memperoleh kesempatan untuk mangamati pengalaman yang pernah dialami fasilitator dan memberikan pertanyan-pertanyaan terkait pengalaman tersebut, serta membagi pengalaman yang dimiliki selama menghadapi siswa terkait tentang KSA di sekolah. Fasilitator memberikan vidio kasus KSA pada anak berkebutuhan khusus, membuat peserta tertarik untuk memberikan perhatian dan mendiskusikan dengan fasilitator. Hal tersebut tampak bahwa para guru kelompok eksperimen memberikan perhatian selama proses pelatihan.

Penjelasan materi yang disampaikan oleh fasilitator direpresentasikan secara verbal dan simbolik oleh peserta. Saat evaluasi materi, fasilitator menyanyakan materi yang sudah disampaikan pada pertemuan sebelumnya. Beberapa guru menjawab pertanyaan dengan stimulus verbal dari fasilitator terlebih dahulu, kemudian guru baru ingat tentang materi yang sudah dipelajari, namun ada juga guru yang diberikan stimulus simbol baru bisa mengingat materi yang sudah dipelajari.

Pada saat pretes keterampilan menyampaikan prevensi KSA, seluruh guru menyampaikan materi prevensi KSA pada siswa tidak terarah dan tanpa media pendukung. Seluruh guru mengaku merasa kebingungan akan materi yang akan disampaikan seperti apa dan merasa tidak mampu dapat menyampaikan materi prevensi KSA kepada anak berkebutuhan khusus. Akan tetapi setelah diberikan pelatihan, guru sudah mengetahui meteri dan bagaimana menyampaikan prevensi KSA kepada anak berkebutuhan khusus dengan tepat, dan memiliki keyakinan mampu untuk mengajarkan prevensi KSA kepada siswa berkebutuhan khusus. Sebagian besar guru menggunakan media pendukung saat menyampaikan prevensi KSA kepada siswa (postes), seperti flip-chat rambu-rambu KSA, vidio perkembangan, dan cerita dengan gambar. Kemudian guru meminta siswa untuk berkomentar dan menjawab pertanyaan guru, ketika guru memperlihatkan gambar perilaku boleh dan tidak boleh dilakukan siswa terkait situasi yang menimbulkan terjadinya KSA. Hal yang dilakukan para guru (kelompok eksperimen) pada saat menyampaikan prevensi KSA (postes), sebagian besar perilaku mereka memodifikasi contoh-contoh yang diberikan saat pelatihan.

Belajar melalui pengamatan menjadi efektif ketika peserta memiliki motivasi yang tinggi untuk dapat melakukan tingkah laku modelnya. Motivasi yang dimiliki oleh guru kelompok eksperimen terlihat baik. Hal ini tampak pada semangat dan antusias guru setiap sesi serta selalu datang tepat waktu ketika pelatihan. Motivasi yang baik pada peserta kelompok eksperimen merupakan salah satu faktor yang menyebabkan peningkatan skor postes pada keterampilan menyampaikan prevensi KSA. Peningkatan skor keterampilan menyampaikan prevensi KSA juga dialami oleh kelompok kontrol, namun tidak secara signifikan.

Hasil pretes efikasi mengajar kelompok kontrol berada pada kategori tinggi. Namun ada beberapa hal yang perlu diperhatikan saat menggunakan skala sebagai alat ukur. Menurut Azwar (2002), pengukuran atribut psikologis sangat sulit bahkan mungkin tidak akan pernah dapat dilakukan dengan validitas, reliabilitas, dan objektivitas yang tinggi. Maka dari itu prosedur konstruksi skala psikologis menjadi lebih rumit, harus dilakukan dengan penuh perencanaan dalam mengikuti barbagai langkah metodologis, sehingga sumber eror dapat ditekan sedikit mungkin.

Menurut Asch, Jedrziewski \& Christakis (1997), atribut psikologi dalam diri manusia stabilitasnya tidak tingggi, apalagi untuk menjangkau subjek penelitian yang memiliki karakteristik faking good, artinya subjek penelitian memberikan jawaban positif agar dinilai baik. Motivasi subjek yang 
memberikan jawaban tersebut beragam, ada yang sengaja untuk memberikan impresi yang positif, menjaga privasi pribadi atau penolakan terhadap proses pengukuran yang dilakukan. Respons tersebut dilakukan dengan memberikan jawaban distortif dari kenyataan sesungguhnya. Respons tersebut memberikan dampak yang besar dalam kesimpulan yang diambil oleh seorang peneliti (Widhiarso \& Suhapti, 2009). Nederhof (1985) menemukan bahwa adanya respons tersebut dapat mengganggu validitas instrumen pengukuran yang dipakai (Widhiarso \& Suhapti, 2009). Jawaban yang tidak valid karena guru cenderung faking good, sehingga berpengaruh terhadap skor postes yang tinggi pada kelompok kontrol, akibatnya penelitian yang dilakukan tidak signifikan pada efikasi mengajar prevensi KSA.

Menurut Bandura (1986) tidak mudah membentuk efikasi diri seseorang, hal itu karena berkaitan dengan proses kognitif, sosial dan perilaku walaupun memiliki pengetahuan dan keterampilan yang baik. Sesungguhnya pengetahuan dan keterampilan merupakan faktor pendukung tingginya efikasi diri seseorang, akan tetapi hal itu tidak cukup karena perlu adanya self-efficacy judgment yaitu individu menilai bahwa dirinya memiliki keyakinan akan kemampuan yang dimiliki. Apabila self-efficacy judgment sudah tertanam dalam diri maka individu akan berlatih untuk menilai bahwa dirinya memiliki kemampuan dan yakin dengan kemampuan yang dimiliki. Hal tersebut juga didukung oleh adanya sumber-sumber efikasi. Efikasi diri dapat diperoleh, diubah, ditingkatkan atau diturunkan, melalui salah satu atau kombinasi empat sumber, yakni pengalaman menguasai sesuatu prestasi (performance accomplishment), pengalaman vikarius (vicarious experience), persuasi sosial (social persuation) dan pembangkitan emosi (emotional / physiological states). Apabila individu memiliki pengetahuan, keterampilan, self-efficacy judgment dan sumber-sumber efikasi maka akan memiliki efikasi diri yang tingggi. Hal ini berbeda dengan kelompok eksperimen dalam penelitian ini, dimana pengetahuan dan keterampilan dalam menyampaikan prevensi KSA tinggi, akan tetapi efikasi mengajar prvensi KSA rendah. Hal itu karena para guru tidak memiliki self-efficacy judgment terkait menyampaikan prevensi KSA pada siswanya yang mengalami keterbelakangan mental, sehingga guru merasa dirinya tidak yakin dengan kemampuannya untuk mengajarkan prevensi KSA pada anak berkebutuhan khusus, walaupun memiliki motivasi yang tingggi. Sesuai dengan pernyataan beberapa guru (kelompok eksperimen) saat postes bahwa guru menilai bahwa dirinya tidak memiliki kemampuan untuk mengajarkan prevensi KSA kepada siswa berkebutuhan khusus dan lemah mental, walaupun guru bersemangat untuk mengajar. Hal tersebut yang menyebabkan tidak ada perubahan pada efikasi mengajar guru pada kelompok eksperimen, dan tidak adanya perbedaan antara kelompok yang diberi perlakuan dan kelompok yang tidak diberi perlakukan.

Penelitian yang dilakukan oleh Ruble, Usher \& McGrew (2011) menunjukkan guru yang memiliki pengalaman lama dalam mengajar anak autis belum tentu memiliki efikasi mengajar yang tingggi, hal ini berkaitan dengan siswa yang diajar yaitu anak dengan gangguan autisme, sehinggga membuat guru tidak yakin bahwa apa yang diajarkan dapat diterima dengan baik oleh siswa, sekalipun guru memiliki kompetensi dalam mengajar anak autis. Selain itu guru yang memiliki tingkat burnout tinggi maka efikasi mengajarnya rendah, hal ini menunjukkan bahwa kondisi fisik/emosi mempengaruhi efikasi guru dalam mengajar anak autis. Namun dalam penelitian ini persuasi sosial tidak berkorelasi dengan efikasi mengajar guru autis.

Metode yang digunakan dalam pelatihan adalah ceramah, diskusi dan role-play. Selama pelatihan fasilitator menyampaikan materi dengan media pendukung flip-chart, video kasus dan gambar. Fasilitator meminta guru untuk role-play menyampaikan prevensi KSA kepada siswa berkebutuhan khusus, guru menggunakan media flip-chart, gambar dan ada juga yang menggunakan kartu bergambar yang sudah dibuat pada sesi "memaksimalkan media pendukung". Selain itu bahasa yang digunakan guru juga sudah disesuaikan dengan kemampuan dan karakteristik siswa ABK, sehingga mudah 
dipahami. Setelah melakukan role-play peserta mendapat feedback dari fasilitator sehingga peserta mendapat kritik dan saran untuk mengembangkan kemampuan dalam menyampaikan prevensi KSA pada siswa SLB-C. Selain sudah menggunakan media pendukung dalam menyampaikan prevensi KSA, penjelasan materi yang disampaikan oleh guru saat postes sudah sistematis dibandingkan pada saat pretes. Hal ini menyebabkan skor keterampilan menyampaikan prevensi KSA dari pretes ke postes pada kelompok eksperimen meningkat.

Penelitian ini memiliki beberapa keterbatasan, yaitu tidak dilakukan follow up setelah postes, sehingga penelitian ini hanya dapat melihat efek pelatihan dalam jangka pendek saja. Keterbatasan yang lain adalah tingginya motivasi subjek penelitian,pada kelompok eksperimen dan kelompok kontrol sehingga sulit untuk dikendalikan.

\section{Kesimpulan dan Saran}

Hasil analisis anava campuran pada penelitian ini menunjukkan bahwa program " jari peri" dapat meningkatkan keterampilan menyampaikan prevensi KSA pada kelompok eksperimen. Artinya program "jari peri" dapat meningkatkan keterampilan menyampaikan prevensi KSA pada guru SLB-C. Namun, program "jari peri" tidak dapat meningkatkan efikasi mengajar prevensi KSA pada guru SLBC. Dengan demikian dianjurkan bagi peneliti yang hendak menggunakan modul ini harap menyempurnakan modul sesuai dengan saran penelitian.

Berdasarkan temuan, penelitian berikutnya dapat melakukan follow up agar dapat melihat efek pelatihan program "jari peri" (guru ajari proteksi diri) pada guru SBL-C jangka panjang, termasuk mengamati keberlangsungan program. Bagi peneliti selanjutnya yang hendak menggunakan modul ini, sebaiknya dilakukan monitoring dan evaluasi setelah pelatihan sebagai penyempurna modul "jari peri". Menggunakan aitem pengecoh dalam skala dan mengganti urutan aitem skala sehingga berbeda saat pretes dan postesnya, hal ini dilakukan agar tidak terjadi ceiling effect dan faking good terhadap respon skala.

\section{Daftar Pustaka}

Abramson, W. H. (2002). Kid\&TeenSAFE: An Abuse Prevention Program for Youth Disabilities. Journal of National Resource Center on Domestic Violence

Azwar, S. (2001). Asumsi-asumsi dalam Inferensial Statistika. Buletin Psikologi. Tahun IX. No.1.Hal 8-17

Azwar, S. (2005). Signifikan atau Sangat Signifikan?. Buletin Psikologi. Vol. 13. No.1

Bandura, A. (1986). Social Foundations of Thought and Action, A Social Cognitive Theory. Englewood Cliffs, New Jersey: Prentice Hall

Baginsky, M \& Macpherson, P. (2005). Training Teachers to Safeguard Children: Developing a Consistent Approach. Child Abuse Review,14, 317-330.

Barron, I.G., \& Topping, K.J. (2003). School-based Child Sexual Abuse Prevention Programs: The evidance on effectivenees. Journal University of Dunde.

Bloom, M. (1996). Primary Prevention Practises, Issues in Children's and Families' Lives Volume 5. California: Sage Publications 
Cederborga, A. C., Hultmanb, E., \& Rooyc, D. L. (2011). The quality of details when children and youths with intellectual disabilities are interviewed about their abuse experiences. Scandinavian Journal of Disability Research. 1-13

Cerit, Y. (2010). Teacher Efficacy Scale: The Study Of Validity And Reliability And Preservice Classroom Teachers' Self Efficacy Beliefs. Journal of Theory and Practice in Education.

Coe, R. (2002). Paper Presented at The annual Conference of The british Educational Research Association. University of Exeter England. 12-14 September 2012. Diakses dari http:/wwww.dur.ac.uk/r.j.coe/research.htm

Daro, D. A. (1994). Prevention of Child Sexual Abuse. The Future of Children Sexual Abuse Of Children. Vol. 4. No. 2

Feist, J., \& Feist, G.I. (2008). Theories of personality edisi keenam (penerjemah, Yudi. Santoso). Yogyakarta: Pustaka Pelajar

Field, A. (2005). Discovering Statistics Using SPSS. London: Sage Publications. Finkelhor, D. (2009). The Prevention of Childhood Sexual Abuse. Journal of The Future Of Children. Vol. 19 /No. 2

Finkelhor, D., Hammer, H., \& Sedlak, A. J. (2008). Sexually Assaulted Children: National Estimates and Characteristics. Journal of National Incidence Studies of Missing, Abducted, Runaway, and Thrownaway Children. Diakses dari www.ojp.usdoj.go

Gorczyca. W., Gorczyca. A.K., Ziora. K., \& Oświęcimska. J., (2007). Sexual Abuse in Autistic Children as a Risk Factor of Developing of Schizophrenia. Medical University of Silesia in Katowice: Poland. Pp

Hadjam, N. R. \& Widhiarso. (2011). Efikasi Mengajar Sebagai Mediator Peranan Faktor Kepribadian Terhadap Performasi Mengajar Guru. Yogyakarta: Fakultas Psikologi Universitas Gadjah Mada. Humanitas, Vol. VIII No.1 -1

Hall, M., \& Hall, J. (2011). The long-term Effects of Childhood Sexual Abuse: Counseling Implications. Journal of American Asosiation Counseling. Diakses dari http://counselingoutfitters.com/vistas /vistas11

Heather A. Turner, H. A., Vanderminden, J., Finkelhor, D., Hamby, S., \& Shattuck, A. (2011). Disability and Victimization in a National Sample of Children and Youth. Journal of Child Maltreatment 1-2. http://cm.sagepub.com

HIMPSI. (2010). Kode Etik Psikologi Himpunan Psikologi Indonesia,Cetakan Pertama Hasil Kongres XI Himpsi. Jakarta: Pengurus Pusat HIMPSI

http://www.republikaoneline.co.id. (2013, 2013). Kekerasan Seksual pada Anak Dinilai Memburuk. Diakses pada tanggal 16 Maret 2013

Jacobsen, D. R. (1993) Evaluation of A Teacher Training Program for The Identification, Intervention, and Prevention of Child Sexual Abuse. Thesis. Master of Science in Psychology in the School of Natural Sciences California State University. Fresno.

Janet Saul, J. \& Audage, N. C. (2007). Preventing Child Sexual Abuse Within Youth- serving Organizations: Getting Started on Policies and Procedures. U.S. Department Of Health And Human Services Centers for Disease Control and Prevention National Center for Injury Prevention and Control Division of Violence Prevention: Atlanta, Georgia

Kenny, M. C., Capri, V., Reena, R., Kolar, T., Ryan, E. E., \& Runyon, M. K. (2008). Child Sexual Abuse:From Prevention to Self-Protection. Journal of Child Abuse Review. Vol. 17: 36-54. Diakses dari www.interscience.wiley.com

Kinnear, K.L. (2007). Childhood Sexual Abuse (second edition). Santa Barbara: ABC-CLIO, Inc.

Kvam, M. H. (2004). Sexual Abuse of Deaf Children: A Retrospective Analysis of The Prevalence and Characteristics of Childhood Sexual Abuse Among Deaf Adults In Norway. Journal of Child Abuse E Neglect, 3 , 241-251 
Kvam, M. H. (2005). Experiences of Childhood Sexual Abuse among Visually Impaired Adults in Norway: Prevalence and Characteristics. Journal of Visual Impairment E Blindness, 99 (1), 5-14

Larsen, K.H., Andersen, S., \& Plauborg, R. (2010). Prevention of Child Sexual Abuse School and Community Efforts to Prevent and Treat Sexual Abuse. National Institute of Public Health, University of Southern Denmark

Levy, H., \& Packman, W. (2004) Sexual Abuse Prevention for Individuals With Mental Retardation: Considerations for Genetic Counselors. Journal of Genetic Counseling, Vol. 13, No. 3

Lovett, B. B. (2004). Child Sexual Abuse Disclosure: Maternal Response and other Variables Impacting the Victim. Child and Adolescent Social Work Journal, Vol. 21, No. 4

London, K., Bruck, M., Hopkins, J., Ceci, S. J., Shuman, D. W. (2005). DISCLOSURE OF CHILD SEXUAL ABUSE What Does the Research Tell Us About the Ways That Children Tell?. Psychology, Public Policy, and Law the American Psychological Association. Vol. 11, No. 1, 194-226

LPA Yogyakarta. (2006, 2007, 2008). Data Kekerasan Seksual pada Anak. Yogyakarta

Mandell, D.S., Walrath, C. M., Manteuffel, B., Sgro, G., \& Pinto-Martin, j. A. (2005). The Prevalence and Correlates Of Abuse Among Children With Autism Served In Comprehensive Community-Basedmental Health Settings. Journal of Child Abuse and Neglect. 1359-1372

Morano, J.P., (2001). Sexual Abuse of the Mentally Reterded Patient: Medical and Legal Analysis for the Primary Care Physician. Primary Care Companion J Clin Psychiatry.

Molnar, B. E., Buka, S. L., \& Kessler, R. C. (2001). Child Sexual Abuse and Subsequent Psychopathology: Results From the National Comorbidity Survey. American Journal of Public Health. Vol. 91, No. 5

Mukhlis, H., Triaristina, A., Wahyudi, D. A., Kameliwati, F., \& Putri, R. H. (2020). Anxiety Confronts Practice Exam Reviewed from Optimism, Emotional Intelligence, and Social Support on Student of STIKES. Journal of Talent Development and Excellence, 12(2s), 830-842.

Mukhlis, H., Kristianingsih, A., Fitrianti, F., Pribadi, T., Kumalasari, D., Febriyanti, H., Maseleno, A. (2020). The effect of expressive writing technique to stress level decrease of new student at Al-Falah Putri Islamic Boarding School, Margodadi, Tanggamus. Annals of Tropical Medicine and Health, 23 (6). p 192-200. http://doi.org/10.36295/ASRO.2020.23624

Myers, A., \& Hansen, C.H. (2002). Experimental Psychology. Fifth edition. Pacific Grove, CA: Wedsworth Thomson Learning

National Catholic Services LLC. (2003). Practical Advice for Parents on Preventing Child Sexual Abuse. All rights reserved. 1-630-725-0986. Page 1 of 3

National Sexual Violence Resource Center. (2011). Child Sexual Abuse Prevention: Rograms For Children Building An Evidence-Informed Approach. Diakses dari www.nsvrc.org

Nelson-Jones, R. (1982). The theory and Practice of Counselling psychology. London: Holt, Rinehart and Winston

Nitisemito, S. A. (1994). Manajemen Personalia. Edisi Delapan. Jakarta: Ghalia Indonesia

Paramastri, I., Prawitasari, J.E., Prabandari, Y.S dan Ekowarni, E. (2011). Guru Sekolah Dasar Sebagai Agen Pengubah Untuk Prevensi Terhadap Kekerasan Seksual Pada Anak-Anak. Jurnal Manajemen Pelayanan Kesehatan. Vol. 14, Hal. 84-91

Pence, D. M., \& Wilson, C. A. (1994). Reporting and Investigating Child Sexual Abuse. Journal of The Future Of Children Sexual Abuse Of Children. Vol. 4. No. 2 - Summer

Purwadi, I., Hakinatussa'diyah, Mahmud, Zaini, A., Habibi, M. (2002). Hentikan Kekerasan Pada Anak, Seri Pendidikan Keluarga, Kerjasama Unicef \& Lembaga Perindungan Anak NTB, Mataram

Ruble, L. A, Usher, E. L \& McGrew, J. H. (2011). Preliminary Investigation of the Sources of Self-Efficacy Among Teachers of Students with Autism. Journal of Focus on Autism and Other Developmental Disabilities. Sage 
publications. http:/ffocus.sagepub.com

Saul, J., \& Audage, N.C. (2007). Preventing Child Sexual Abuse Within Youth- serving Organizations: Getting Starting on Policies and Procedure. National Center for Injury Prevention and Control. Atlanta Georgia

Supratiknya, A. (2011). Merancang Program dan Modul, Psikoedukasi. Yogyakarta: Universitas Sanata Dharma

Shadish, W.R., Cook, T.D., \& Campbell, D.T. (2002). Experimental and quasi-experimental designed for generalized causal inference. New York: Houghton Mifflin Company

Skarbek, D., Hahn, K., \& Parrish, P. (2009). Stop Sexual Abuse in Special Education: An Ecological Model of Prevention and Intervention Strategies for Sexual Abuse in Special Education. Journal of Sex Disabil, Vol. 27:155-164

Smith, N. (2012). Running head: Child Centered Play Therapy For Sexually Abused Children. Journal of child sexual abuse

Stop It Now-Together We Can Prevent The sexual Abuse of Children. (2007). Do Children Sexually Abuse Other Children? Preventing sexual abuse among children and youth. Journal of Prevent Child Sexual Abuse. Diakses dari: www.stopitnow.org dan info@stopitnow.org

Topping, K. J., \& Barron, L. G. (2009). School-Based Child Sexual Abuse Prevention Programs: A Review of Effectiveness. Review of Educational Research. Journal of University of Dundee. Vol. 79, No. 1, pp. 431-463. 24 Nopember 2013. Diakses dari http://rer.aera.net

Trickett, P. K., Noll, J. G., \& Putnam, F. W. (2011). The Impact of Sexual Abuse on Female Development: Lessons From A Multigenerational, Longitudinal Research Study. Development and Psychopathology Vol. 23 453-476

Thomas, D., Leicht, C., Hughes, C., Madigan, A., Dowell, K. (2002). Emerging Practices In The Prevention Of Child Abuse And Neglect. Journal of Child Abuse and Neglect

Vivolo, A.M., Holland, K.M., Teten, A.L., Holt, M.K. (2010). Developing Sexual Violence Prevention Strategies by Bridging Spheres of Public Health. Journal of Women's Health, 19, 10.

Walsh, K., \& Brandon, L. (2011). Their Children's First Educators: Parents' Views About ChildSexu al Abuse Prevention Education. Journal of Child Fam Stud. Vol. 21:734-746

Widhiarso, W. (2011). Aplikasi anava campuran untuk desain eksperimen pre-post test design. Yogyakarta: Fakultas Psikologi Universitas Gadjah Mada. Diakses pada Desember 2013 melalui www.scribd.com

Widhiarso, W. \& Suhapti, R. (2009). Eksplorasi Karakteristik Item Skala Psikologis yang Rentan terhadap Tipuan Respon. Jurnal Psikologi Fakultas Psikologi Universitas Gadjah Mada. Vol. 36, No. 1, 73 - 91.

Wijayanti, S. (2011). Guru Sebagai Mediator Sosialisasi Kesehatan Reproduksi Pada Siswa Sltp. Tesis. Yogyakarta: Universitas Gadjah Mada 